\title{
Deletion of the mitochondria-shaping protein Opa1 during early thymocyte maturation impacts mature memory $\mathrm{T}$ cell metabolism
}

\author{
Mauro Corrado ${ }^{1,2} \cdot$ Dijana Samardžić ${ }^{1,3} \cdot$ Marta Giacomello $\mathbb{C}^{3} \cdot$ Nisha Rana ${ }^{2} \cdot$ Erika L. Pearce $\mathbb{C}^{2} \cdot$ Luca Scorrano ${ }^{1,3}$
}

Received: 30 July 2020 / Revised: 30 July 2020 / Accepted: 28 January 2021 / Published online: 1 March 2021

(c) The Author(s) 2021. This article is published with open access

\begin{abstract}
Optic atrophy 1 (OPA1), a mitochondria-shaping protein controlling cristae biogenesis and respiration, is required for memory $\mathrm{T}$ cell function, but whether it affects intrathymic $\mathrm{T}$ cell development is unknown. Here we show that OPA1 is necessary for thymocyte maturation at the double negative (DN) 3 stage when rearrangement of the T cell receptor $\beta(T c r \beta)$ locus occurs. By profiling mitochondrial function at different stages of thymocyte maturation, we find that DN3 cells rely on oxidative phosphorylation. Consistently, Opal deletion during early T cell development impairs respiration of DN3 cells and reduces their number. Opal-deficient DN3 cells indeed display stronger TCR signaling and are more prone to cell death. The surviving $\mathrm{Opal}^{-1-}$ thymocytes that reach the periphery as mature T cells display an effector memory phenotype even in the absence of antigenic stimulation but are unable to generate metabolically fit long-term memory $\mathrm{T}$ cells. Thus, mitochondrial defects early during $\mathrm{T}$ cell development affect mature $\mathrm{T}$ cell function.
\end{abstract}

\section{Introduction}

The $\mathrm{T}$ cell repertoire develops from precursor cells migrating from the bone marrow into the thymus where a complex multistep maturation program generates functional $\mathrm{CD}^{+}$and $\mathrm{CD}^{+} \mathrm{T}$ cells able to discriminate self/non-selfantigen [1, 2]. In an early phase of thymocyte development, progenitors lacking expression of the major histocompatibility complex (MHC) co-receptors CD4 and CD8 are defined double negative (DN) cells and are classically divided into DN1-DN4 cells according to the expression of

Edited by E. Baehrecke

Supplementary information The online version contains supplementary material available at https://doi.org/10.1038/s41418021-00747-6.

Mauro Corrado

corrado@ie-freiburg.mpg.de

$\triangle$ Luca Scorrano

luca.scorrano@unipd.it

1 Veneto Institute of Molecular Medicine, Padua, Italy

2 Max Planck Institute of Immunobiology and Epigenetics, Freiburg im Breisgau, Germany

3 Department of Biology, University of Padua, Padua, Italy the surface markers CD44 and CD25 (DN1: CD44 ${ }^{\text {high }} \mathrm{C}$ D25 ${ }^{\text {low }}$; DN2: $\mathrm{CD} 44^{\text {high }} \mathrm{CD} 25^{\text {high }}$; DN3: $\mathrm{CD} 44^{\text {low }} \mathrm{CD} 25^{\text {high }}$; DN4: $\left.\mathrm{CD} 44^{\text {low }} \mathrm{CD} 25^{\text {low }}\right)[2,3]$. After preliminary lineage commitment, thymocytes initiate rearrangement of the T cell receptor $(T c r) \beta$ locus at the DN3 stage [4]. Only cells producing a functional T cell receptor $\beta$ (TCR $\beta$ ) chain are allowed to pass beyond DN3 stage, through a process called $\beta$-selection [2]. DN4 cells then undergo rapid proliferation and differentiate in $\mathrm{CD}^{+} \mathrm{CD}^{+}$double positive (DP) $\mathrm{T}$ cells, where TCR $\alpha$ chain rearrangement takes place $[5,6]$. During the DP stage, only cells with a competent TCR that binds MHC (class I or II) with a low affinity are positively selected [2]. When TCR/MHC affinity is too high, activation-induced cell death (AICD) is triggered to avoid the generation of autoreactive $\mathrm{T}$ cells [2,7]. The class identity of MHC molecules interacting with the TCR dictates the final commitment: T cells binding to MHC-II will become $\mathrm{CD}^{+}$, whereas MHC-I-binding cells will mature into $\mathrm{CD} 8^{+} \mathrm{T}$ cells [2].

The first report describing the role of energy metabolism in thymocyte development dates back to 1978 [8]. Nevertheless, for many years the study of metabolism in thymocytes has been limited to the analysis of the effects of NOTCH and interleukin (IL)-7 signaling on cell survival and growth $[6,9,10]$. More recently, glucose and glutamine were shown to fuel protein O-GlcNAcylation during $\beta$ selection [11]. In addition, deletion of the mitochondrial 
pyruvate carrier 1 , essential for pyruvate entry in the mitochondrial matrix and hence for fueling the tricarboxylic acid (TCA) cycle, impairs thymocyte development at different stages resulting in the generation of abnormally activated $\alpha \beta$ T cells [12]. In line with that, the loss of RAPTOR-mediated mTORC1 activity also disturbs thymocyte metabolism and reciprocal lineage decision between $\alpha \beta$ and $\gamma \delta$ T cells $[13,14]$.

In response to intracellular and extracellular inputs, mitochondrial fusion and fission regulate respiration, apoptosis, and signaling to nucleus and other organelles [15-17]. Dynamin-related protein 1 (DRP1) is the main regulator of mitochondrial fission and in $\mathrm{T}$ cells promotes in vitro migration of lymphocytes, mitochondria localization at immunological synapse, and in vivo cMYCdependent metabolic reprogramming and expansion upon activation [18-20]. Optic atrophy 1 (OPA1) is required for inner mitochondrial membrane (IMM) fusion, apoptosis, cristae morphology, organization of electron transport chain (ETC) supercomplexes and hence respiration [21-23]. In $\mathrm{T}$ cells, OPA1 is necessary to generate long-term $\mathrm{T}$ cell memory in secondary lymphoid organs [24]. Interestingly, both DRP1 and OPA1 coordinate AICD, pivotal for thymocyte negative selection and for effector cell contraction after infection [25-27].

Despite these observations, the role of mitochondrial function and of OPA1 during thymocyte development remains unknown. We found that among $\mathrm{T}$ cell precursors, DN3 cells are characterized by high oxidative phosphorylation (OXPHOS) capacity. Accordingly, OPA1 is required during thymocyte $\beta$-selection and $O p a l$ deficiency alters TCR signaling in thymocytes, resulting in lymphopenia and impaired metabolism of mature $\mathrm{T}$ cells.

\section{Results}

\section{High OXPHOS flags developing thymocytes during $T c r \beta$ locus rearrangement}

During thymocyte development, mitochondrial respiration appears to peak at the DN3 stage [12,13], but it is unclear whether this is the epiphenomenon of mitochondrial biogenesis and increased mass, or due to specific mechanisms regulating mitochondrial fuel utilization/respiration. We therefore profiled mitochondrial membrane potential $(\Delta \psi)$ using the potentiometric dye tetramethyl rhodamine methyl ester (TMRM) and mitochondrial mass with the potentialinsensitive staining MitoTracker Green in different subsets of thymocytes isolated from wild-type (WT) mice. Fluorescence of both dyes increased during the DN1 $\rightarrow$ DN3 transition, suggesting an increase in mitochondrial mass and mitochondrial respiratory capacity during $\beta$-selection, and then it dropped in DN4 thymocytes (Figs. 1A, B, S1A, and S1B). During the DN4 $\rightarrow$ DP transition, MitoTracker Green signal further decreased, whereas TMRM staining increased. In mature thymocytes, MitoTracker Green staining was higher in $\mathrm{CD}^{+}$than in $\mathrm{CD}^{+} \mathrm{T}$ cells; TMRM fluorescence conversely was lower in $\mathrm{CD}^{+} \mathrm{T}$ cells compared the $\mathrm{CD}^{+}$subset (Fig. 1A, B). The finding of a lower membrane potential/mass ratio in DN4 (and $\mathrm{CD} 4^{+}$) compared to the other thymocytes subsets (Fig. 1C) could indicate that these cells mainly rely on oxidative metabolism and hence utilize the electrochemical gradient for ATP generation, or that their mitochondrial respiration is inactive. We therefore measured also mitochondrial oxidative capacity in bulk thymocytes and in purified DN3 and DN4 thymocytes. Seahorse analyses of oxygen consumption rates (OCR) and extracellular acidification rates (ECAR) to follow mitochondrial OXPHOS and glycolysis indicated that bulk thymocytes were largely oxidative, with high spare respiratory capacity (SRC) after mitochondrial uncoupling with fluoro-carbonyl cyanide phenylhydrazone (FCCP) (Fig. 1D-F). Low concentrations of etomoxir, which block carnitine palmitoyltransferase 1a and thus mitochondrial fatty acid oxidation [28], did not curtail maximal respiration, SRC, and OCR/ECAR ratio, suggesting that fatty acids are not the preferential fuel for OXPHOS in total thymocytes (Fig. 1D-G). When we increased the granularity of our analysis, we found that both basal and maximal OCR and ECAR were higher in DN3 compared to DN4 cells (Fig. 1H, I). Normalization to initial values showed higher SRC and maximal respiration in DN3 cells (Figs. 1J and S1C), while lower OCR/ECAR ratio and higher maximal glycolytic rate in DN4 cells (Figs. $1 \mathrm{~K}$ and S1D). These results reveal that the lower mitochondrial membrane potential/mitochondrial mass ratio recorded in DN4 cells does not reflect active mitochondrial respiration, but likely mitochondrial inactivity; moreover, they indicate that the increased mitochondrial mass of DN3 cells is accompanied by higher rates of basal respiration. Finally, the excess SRC recorded in DN3 cells suggests that mitochondria of these immature $\mathrm{T}$ cells might be structurally organized to efficiently utilize fuels when maximal respiration is stimulated.

\section{Conditional Opa1 deletion impairs thymocyte development and mitochondrial metabolism at $\beta$ - selection stage}

Our metabolic and cytofluorimetric profiling supported a role for mitochondrial respiration at the DN3 stage of pre- $\mathrm{T}$ cells. Interestingly, memory $\mathrm{T}\left(\mathrm{T}_{\mathrm{M}}\right)$ cells display similar metabolic features and deletion of the mitochondria-shaping protein OPA1 not only alters the metabolic signature of $\mathrm{T}_{\mathrm{M}}$ cells, but it also skews them toward an effector $\mathrm{T}\left(\mathrm{T}_{\mathrm{E}}\right)$ cell 
A

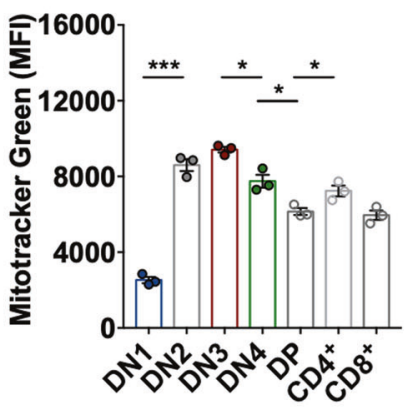

D

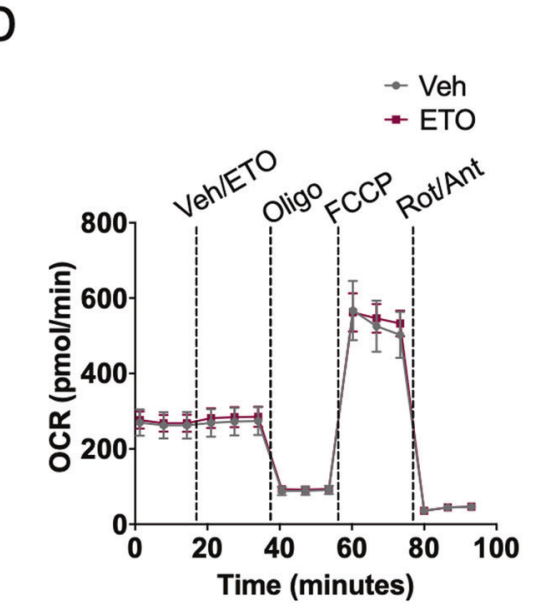

$\mathrm{H}$

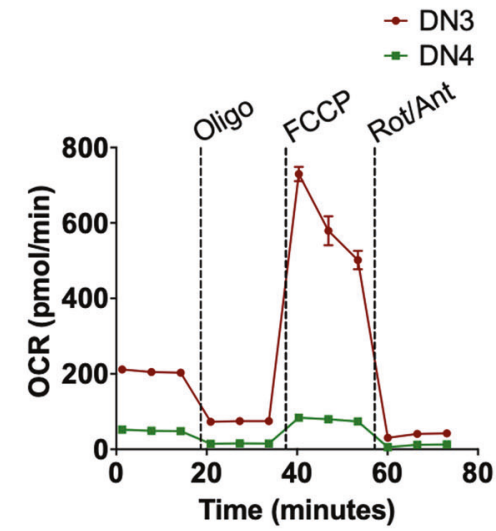

B

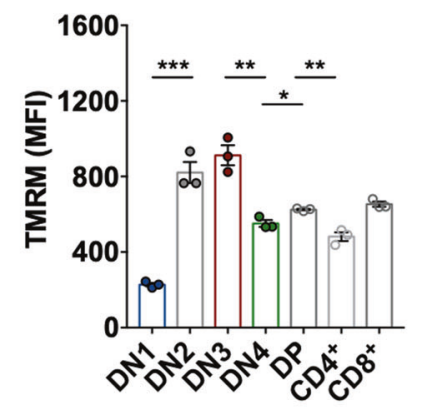

E

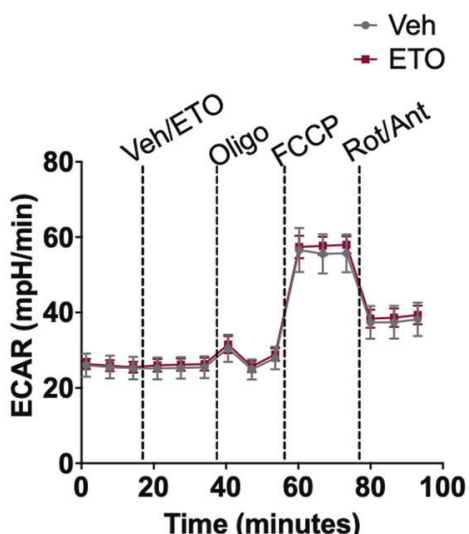

I

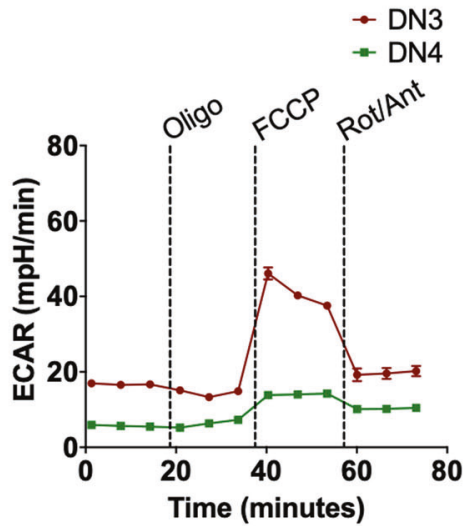

C

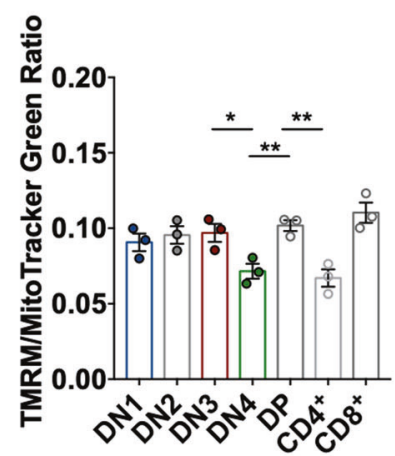

F

- Veh

G

- Veh

- ETO
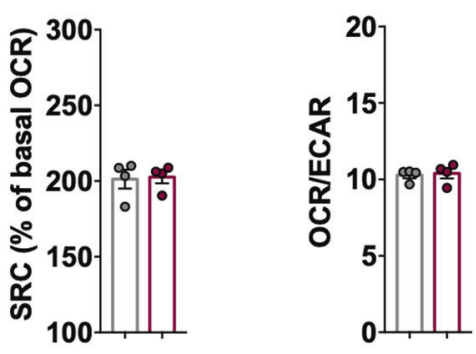

J

- DN3

- DN4

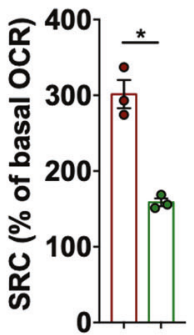

K

- DN3

- DN4

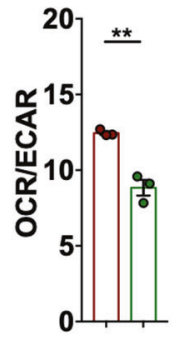

Fig. 1 High OXPHOS flags developing thymocytes at $\beta$-selection stage. A Quantification of mitochondrial mass measured with MitoTracker Green in WT thymocytes analyzed by flow cytometry. Data are mean $\pm \operatorname{SEM}(N=3)$. B Quantification of mitochondrial membrane potential measured with TMRM in WT thymocytes analyzed by flow cytometry. Data are mean $\pm \operatorname{SEM}(N=3)$. C Mitochondrial membrane potential/mitochondrial mass ratio expressed as TMRM/Mitotracker green ratio in WT;Lck-Cre ${ }^{+}$thymocytes analyzed by flow cytometry. Data are mean $\pm \operatorname{SEM}(N=3)$. D Oxygen consumption rate $(\mathrm{OCR})$ of WT thymocytes at baseline and after exposure to vehicle/etomoxir, oligomycin (Oligo), FCCP, and rotenone/antimycin (Rot/Ant). Data are representative of three independent experiments ( $N=4$ /group). $\mathbf{E}$ Extracellular acidification rate (ECAR) of WT thymocytes at baseline and after exposure to vehicle/etomoxir, oligomycin (Oligo), FCCP, and rotenone/antimycin (Rot/Ant). Data are representative of three independent experiments $(N=4 /$ group $)$. F SRC of WT thymocytes treated as in $(\mathbf{D})$. Data are mean \pm SEM $(N=4)$. G OCR/ECAR ratio of WT thymocytes treated as in $(\mathbf{D})$. Data are mean \pm SEM $(N=4)$. $\mathbf{H}$ WT DN3 and DN4 thymocytes were sorted and OCR was measured at baseline and after exposure to oligomycin (Oligo), FCCP, and rotenone/antimycin (Rot/Ant). Data are mean $\pm \operatorname{SEM}(N=3)$. I WT DN3 and DN4 thymocytes were sorted and ECAR was measured at baseline and after exposure to oligomycin (Oligo), FCCP, and rotenone/antimycin (Rot/Ant). Data are mean $\pm \operatorname{SEM}(N=3)$. J SRC of WT DN3 and DN4 thymocytes treated as in $(\mathbf{E})$. Data are mean \pm SEM $(N=3)$. $\mathrm{K}$ OCR/ECAR ratio of WT DN3 and DN4 thymocytes treated as in (E). Data are mean $\pm \operatorname{SEM}(N=3)$. 
phenotype [24]. We first checked OPA1 levels during the different developmental stages of DN thymocytes. OPA1 expression was sustained throughout DN thymocyte development (Fig. S2A). Given the central role of OPA1 in mitochondrial metabolism and its high expression during $\mathrm{T}$ cell development, we sought to investigate if deletion of Opal affected the metabolic and immunological profiles of thymocytes. To ablate Opal from the DN stage of early $\mathrm{T}$ cell development, we crossed Opa ${ }^{\mathrm{t} / \mathrm{fl}}$ [23] with Lck-Cre mice. Because Lck-Cre expression can per se affect thymocyte development $[29,30]$, we always compared Opa ${ }^{\mathrm{f} / \mathrm{f}}$; $\mathrm{Lck}^{-\mathrm{Cre}^{+}}$mice with their littermates expressing only LckCre (hereafter referred to as WT;Lck-Cre ${ }^{+}$, Fig. S2B, C). Efficient reduction of OPA1 levels was confirmed by immunoblotting of thymocyte lysates (Fig. S2D). To study mitochondrial morphology directly ex vivo, we crossed WT and $\mathrm{Opa}^{\mathrm{f} / \mathrm{flf}} ; \mathrm{Lck}^{-\mathrm{Cre}^{+}}$mice to a reporter mouse driving expression of YFP targeted to the mitochondrial matrix (mtYFP) in cells where Cre recombinase is active [31]. The offspring (hereafter WT;Lck-Cre ${ }^{+} ; \mathrm{mtYFP}^{\mathrm{tg} /+}$ and Opa ${ }^{\mathrm{f} / \mathrm{fl}}$; Lck-Cre $^{+} ; \mathrm{mtYFP}^{\mathrm{tg} /+}$ mice) stably expresses mtYFP in thymocytes upon Lck-Cre activation and allows imaging of mitochondria in freshly purified thymocytes. Confocal imaging of mtYFP revealed indeed the expected fragmentation in Opal-deficient cells compared to the WT counterparts (Fig. 2A). Moreover, electron micrographs showed cristae remodeling and disruption upon Opal deletion (Fig. 2B). When we analyzed the immunophenotype of Opal-deficient thymi, we found a threefold reduction in total cellularity (Fig. 2C). Frequencies of DP thymocytes were reduced, whereas the $\%$ of $\mathrm{DN}$ cells appeared to increase (Fig. 2D, E). In absolute numbers, DP, $\mathrm{CD} 4^{+}$, and $\mathrm{CD}^{+}$cells were, however, all reduced (Fig. 2F). This observation led us to hypothesize that $\mathrm{Opal}$ deletion during $\mathrm{T}$ cell development affected the DN $\rightarrow$ DP transition. Thus, we analyzed thymic development at the earlier stages of DN $\mathrm{T}$ cell progenitors. Frequency and total number of DN2, but especially DN3 cells were reduced in $\mathrm{Opa}^{\mathrm{f} / \mathrm{fl}} ; \mathrm{Lck}$-Cre ${ }^{+}$ mice compared to WT littermates (Fig. 2G-I). Expression of the NOTCH1-dependent gene CD25 was curtailed, possibly reflecting altered IL-2 signaling and $\beta$-selection [3, 32, 33] (Fig. 2G). To understand whether lack of OPA1 indeed changed the metabolic profiles of $\mathrm{T}$ cells undergoing $\beta$-selection, we sorted DN3 and DN4 cells from WT;Lck$\mathrm{Cre}^{+}$and $\mathrm{Opal}^{\mathrm{t} / \mathrm{ft}} ; \mathrm{Lck} \mathrm{Cre}^{+}$mice and analyzed their OCR (Fig. 2J). The high basal and maximal respiration observed in WT;Lck-Cre ${ }^{+}$DN3 cells was lost in Opa $1^{\mathrm{f} / \mathrm{fl}} ;$ Lck-Cre $^{+}$ DN3 cells, indicating that OPA1 expression is crucial for the mitochondrial phenotype of DN3 cells (Fig. 2J, K). The mitochondrial respiration defects observed in Opal-deficient DN3 thymocytes were not a bystander effect of different mitochondrial mass or membrane potential that remained unaltered between WT; $\mathrm{Lck}_{-}-\mathrm{Cre}^{+}$and Opa ${ }^{\mathrm{fl} / \mathrm{fl}}$;
Lck-Cre $^{+}$DN3 and DN4 cells (Fig. S3A, B). Alteration of metabolism during $\mathrm{T}$ cell development skews $\alpha \beta$ thymocytes into $\gamma \delta$ differentiation [13]. However, TCR $\alpha \beta$ and $\mathrm{TCR} \gamma \delta$ populations or expression of the IL-7 receptor CD127 in both total thymocytes (Fig. S4A-D) and in DN cells (Fig. S4E-H) were not affected by Opal deletion.

We next addressed whether OPA1 overexpression affected thymocyte development. To this end, we performed an immune characterization of $\mathrm{Opa} 1^{\mathrm{TG}}$ mice that mildly overexpress OPA1 in all tissues [23]. Thymocyte development both at advanced developmental stage at DP $\rightarrow$ SP transition as well as early DN3 $\rightarrow$ DN4 transition and $\beta$ selection was not affected (Fig. S5A, B). Similarly, mature $\mathrm{T}$ and $\mathrm{B}$ cell populations were not altered by OPA1 overexpression (Fig. S5C, D).

Altogether, these data indicate that OPA1 is required for mitochondrial respiration and thymocyte development during $\beta$-selection.

\section{Opa1-deficient thymocytes are more susceptible to TCR stimulation and apoptosis}

To gain insights into the potential mechanism by which Opal deletion impacts $\beta$-selection, we performed RNA sequencing (RNAseq) analysis of sorted DN3 and DN4 Wt and Opal-deleted T cells. While this approach had been informative to define the role of mitochondrial dynamics in cardiac development and angiogenesis [34, 35], it only revealed mild overall differences between Wt and Opal knockout thymocytes. Indeed, when we performed a principal component analysis on the RNAseq data, we observed a major separation only between DN3 and DN4 subpopulations, irrespective of Opal deletion (Fig. 2L). Gene set enrichment analysis of differentially expressed genes between WT;Lck-Cre ${ }^{+}$DN3 and DN4 cells showed, as expected, modulation of NOTCH signaling and Il2ra (CD25) downregulation during $\beta$-selection, confirming cell population identity (Fig. S6). Despite this overall similarity between WT;Lck-Cre ${ }^{+}$and Opa ${ }^{\text {fl/fl }} ;$ Lck$\mathrm{Cre}^{+}$cells, the expression of 13 genes was significantly altered in Opal-deficient cells (Fig. 2M, N). Seven genes were less expressed in Opal-deficient DN3 cells and plummeted even more at the DN4 stage; of these, six were subunits of the ETC encoded by mitochondrial DNA (mtDNA) (Fig. 2N). We were not surprised to find that these genes were less expressed, because long-term Opal deletion impairs mtDNA translation [23]. Interestingly, two genes that are normally expressed at low levels in WT DN3 and even less in DN4 cells were upregulated in both DN3 and DN4 Opal-deficient T cells: Cox6a2 coding for a respiratory chain subunit that stabilizes dimers of complex IV [36]; and Asparagine synthetase (Asns), coding for the enzyme that synthetizes asparagine from aspartate [37] and 
A
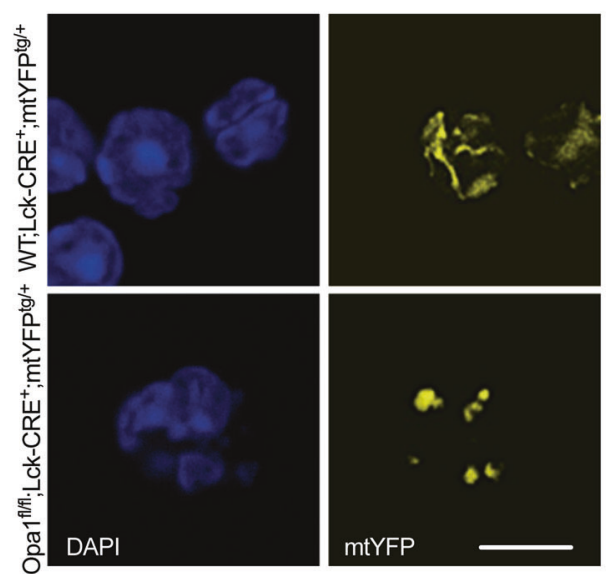

D
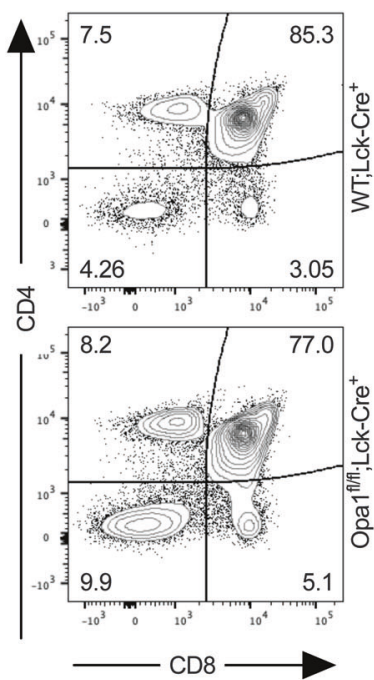

J

- Wt:LCK-CRE ${ }^{+}$DN3

- Wt:Lck-CRE ${ }^{+}$DN4

- Opa $1^{1 / f / i}:$ Lck-CRE ${ }^{+}$DN3

- Opa $1^{1 / 1 / 1}$ :Lck-CRE ${ }^{+}$DN4

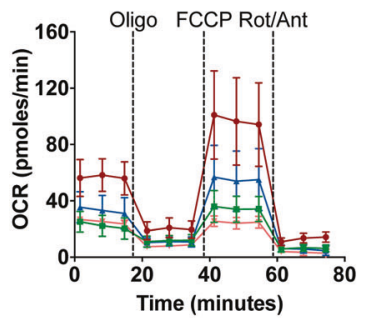

$\mathrm{F}$

$\mathrm{K}$

- Wt:Lck-CRE ${ }^{+}$DN3

- Wt:LCk-CRE ${ }^{+}$DN4

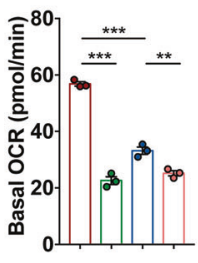

B

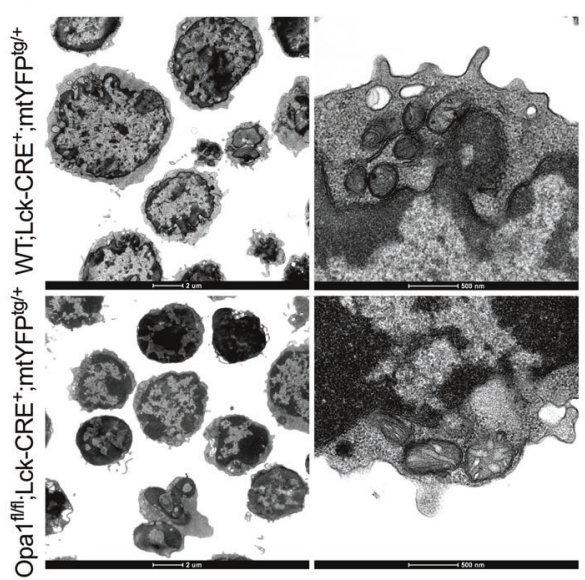

G
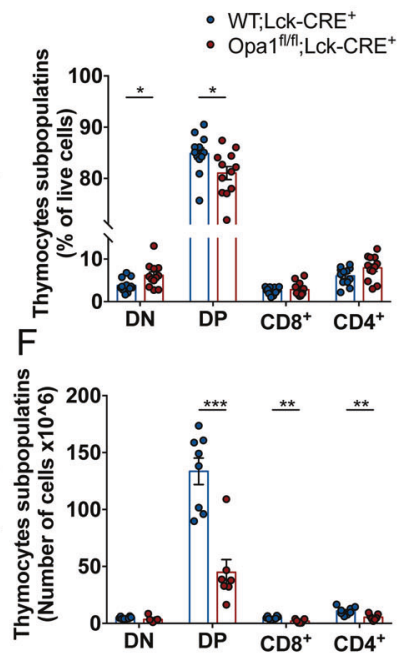

- Opa1 1/ffl:Lck-CRE ${ }^{+}$DN3

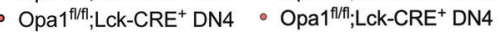

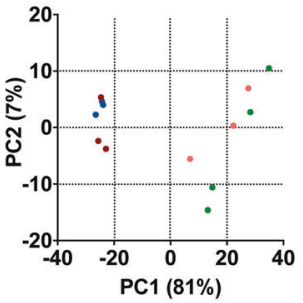

$\mathrm{H}$
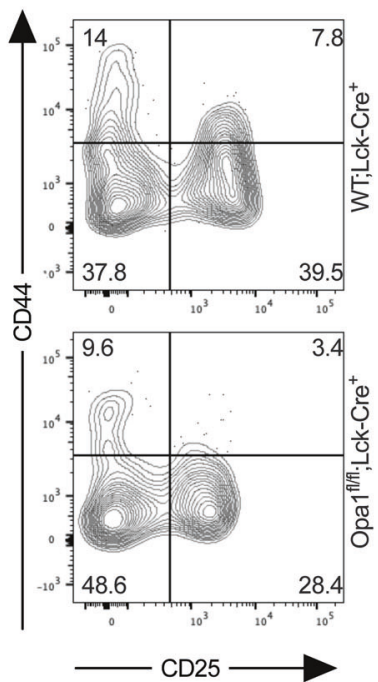

C

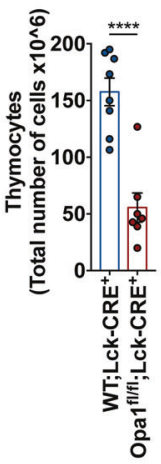

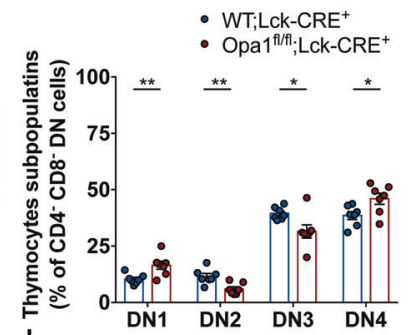
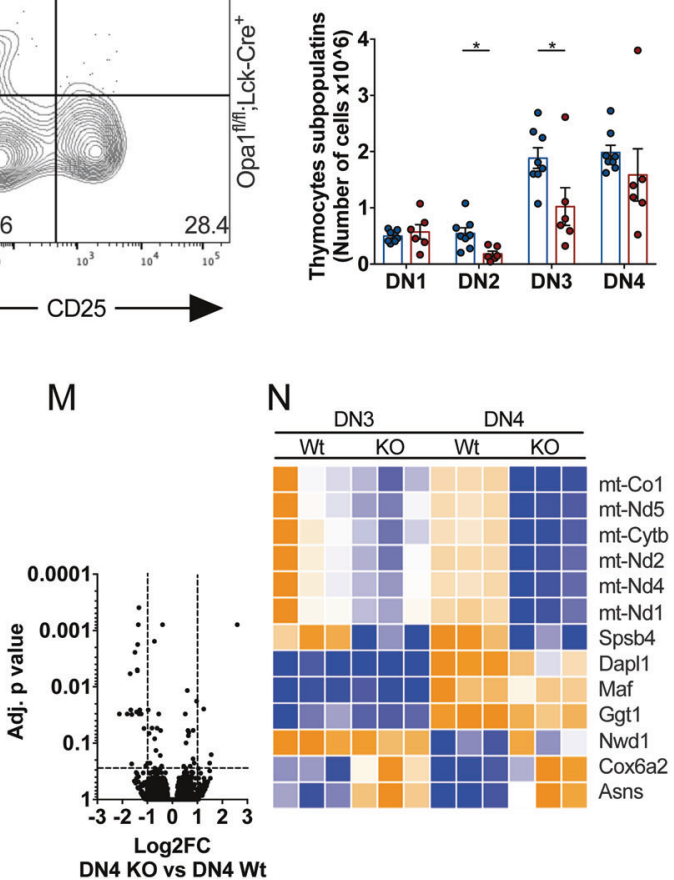

a relapse gene in early $\mathrm{T}$ cell precursor acute lymphoblastic leukemia [38]. Overexpression of Cox6a2 can reflect a compensatory process that stabilizes respiratory chain supercomplexes, otherwise unstable in $\mathrm{Opal}^{-1-}$ cells [23]. Asparaginase upregulation could reflect the attempt to dispose of the aspartate that accumulates because of mitochondrial dysfunction and reduced TCA cycle flux. Indeed, levels of aspartate are reduced in Opal-deficient neurons and in plasma of patients with autosomal dominant optic atrophy caused by OPAI mutations [39]. Nevertheless, we failed to find a unique transcriptional signature that could explain why we found less DN3 cells in Opal- 
Fig. 2 Opa1 deficiency impairs thymocyte development at $\beta$ selection stage. A Representative confocal images of mtYFP fluorescence in thymocytes freshly isolated from WT;Lck-Cre ${ }^{+} ; \mathrm{mtYFP}^{+}$ and $\mathrm{Opa}^{\mathrm{fl} / \mathrm{f}} ; \mathrm{Lck}^{-\mathrm{Cre}^{+}} ; \mathrm{mtYFP}^{+}$mice. Scale bar: $5 \mu \mathrm{m}$. B Representative electron micrographs of thymocytes freshly isolated from WT; Lck-Cre $^{+}$and Opa ${ }^{\mathrm{f} / \mathrm{fl}} ;$ Lck-Cre $^{+}$mice. Scale bars: $2 \mu \mathrm{m}$ or $500 \mathrm{~nm}$ as indicated. C Total thymocyte cellularity of WT;Lck-Cre ${ }^{+}$and Opa ${ }^{\mathrm{fl} / \mathrm{fl}}$; $\mathrm{Lck}-\mathrm{Cre}^{+}$mice. Each symbol represents an individual mouse. Data are shown as flow scatter dot plots with mean \pm SEM bars $(N=7 / 8$ each group). D Representative flow cytometry of DN, DP, CD4 ${ }^{+}, \mathrm{CD} 8^{+}$ thymocyte subsets in WT;Lck-Cre ${ }^{+}$and $\mathrm{Opa}^{\mathrm{f} / / \mathrm{fl}} ;$ Lck-Cre $^{+}$mice. $\mathbf{E}$ Frequencies of DN, DP, CD4 ${ }^{+}, \mathrm{CD}^{+}$thymocyte subsets in WT;Lck$\mathrm{Cre}^{+}$and $\mathrm{Opa1} 1^{\mathrm{f} / \mathrm{fl}} ; \mathrm{Lck}^{-C r e^{+}}$mice. Each dot represents an individual mouse ( $N=12$ each group). Mean \pm SEM are reported. F Cellularity of DN, DP, CD4 ${ }^{+}, \mathrm{CD} 8^{+}$thymocyte subsets in WT;Lck-Cre ${ }^{+}$and $\mathrm{Opa}^{\mathrm{f} / \mathrm{fl}} ; \mathrm{Lck}^{-C r e}{ }^{+}$mice. Each dot represents an individual mouse $(N=8$ each group). Mean \pm SEM are reported. G Representative flow cytometry of DN1-DN4 subsets (gated on lineage-negative DN thymocytes) in WT;Lck-Cre ${ }^{+}$and Opa $1^{\mathrm{f} / \mathrm{fl}} ; \mathrm{Lck}-\mathrm{Cre}^{+}$mice. $\mathbf{H}$ Frequencies of DN1-DN4 thymocyte subsets (gated on lineage-negative DN thymocytes) in WT;Lck-Cre ${ }^{+}$and $\mathrm{Opal}^{\mathrm{f} / \mathrm{fl}} ; \mathrm{Lck}^{-\mathrm{Cre}^{+}}$mice. Each dot represents an individual mouse ( $N=7$ each group). Mean \pm SEM are reported. I Cellularity of DN1-DN4 thymocyte subsets (gated on lineage-negative DN thymocytes) in WT;Lck-Cre ${ }^{+}$and Opa $1^{\mathrm{f} / \mathrm{fl}} ; \mathrm{Lck}-$ $\mathrm{Cre}^{+}$mice. Each dot represents an individual mouse $(N=6 / 8$ each group). Mean \pm SEM are reported. J DN3 and DN4 thymocytes were sorted from WT;Lck-Cre ${ }^{+}$and Opa ${ }^{\mathrm{f} / / \mathrm{f}} ; \mathrm{Lck} \mathrm{Cre}^{+}$mice and OCR was measured at baseline and after exposure to oligomycin (Oligo), FCCP, and rotenone/antimycin (Rot/Ant). Data are shown as mean \pm SEM $(N$ $=4$ /group). $\mathbf{K}$ Basal OCR of DN3 and DN4 thymocytes isolated from $\mathrm{WT} ; \mathrm{Lck}-\mathrm{Cre}^{+}$and $\mathrm{Opa}^{\mathrm{fl} / \mathrm{fl}} ;$ Lck-Cre $^{+}$mice. Data are shown as mean \pm SEM ( $N=4$ /group). L Principal component analysis of gene expression of DN3 and DN4 thymocytes isolated from WT;Lck-Cre ${ }^{+}$and $\mathrm{Opa1}^{\mathrm{f} / \mathrm{f} / \mathrm{l}} ; \mathrm{Lck} \mathrm{Cre}^{+}$mice. M Gene expression of DN4 Opa $1^{\mathrm{f} / \mathrm{f}} ; \mathrm{Lck}^{-\mathrm{Cre}^{+}}$ versus DN4 WT;Lck-Cre ${ }^{+}$thymocytes analyzed by RNAseq. $\mathbf{N}$ Heatmap visualization of the 13 significantly differentially expressed genes between DN4 Opa1 ${ }^{\mathrm{f} / \mathrm{fl}} ; \mathrm{Lck}^{-C r e}{ }^{+}$versus DN4 WT;Lck-Cre ${ }^{+}$ thymocytes. $N=3$ /group.

deficient thymi. We therefore turned our attention to the

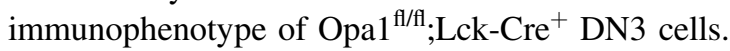

Lower CD25 expression in Opa $1^{\mathrm{f} / \mathrm{fl}} ;$ Lck-Cre $^{+} \mathrm{DN} 3$ cells (Fig. 2G) could reflect different TCR signaling strength and thus a differential activation status of WT; $\mathrm{Lck}_{-} \mathrm{Cre}^{+}$and $\mathrm{Opa}^{\mathrm{f} / / \mathrm{fl}} ; \mathrm{Lck}-\mathrm{Cre}^{+}$thymocytes [3, 40]. Because upregulation of CD5 and CD69 during antigen stimulation positively correlates with the strength of the TCR signaling [41, 42], we analyzed their expression levels. Levels of both CD5 and CD69 were higher in DP Opa ${ }^{\mathrm{f} / \mathrm{lf}} ;$ Lck-Cre $^{+}$thymocytes, suggesting stronger TCR signaling in Opal-deficient T cells (Fig. 3A, B). TCR engagement leads to endoplasmic reticulum $\mathrm{Ca}^{2+}$ release and CRAC channels opening on the cell membrane [43], ultimately resulting in $\mathrm{Ca}^{2+}$-dependent cell death [44]. Although immediately after isolation levels of apoptosis were not different in WT; $\mathrm{Lck}_{-} \mathrm{Cre}^{+}$and Opa ${ }^{\mathrm{t} / \mathrm{f}}$; Lck-Cre $^{+}$thymocytes (Fig. S7A), Opal-deficient T cells were more sensitive to spontaneous cell death after $24 \mathrm{~h}$ in culture (Fig. 3C). Supplementation with IL-7 did not differentially rescue Wt or Opal-deficient cells from apoptosis (Fig. 3C), in line with the comparable expression of CD127
(IL-7 receptor) in WT;Lck-Cre ${ }^{+}$and $\mathrm{Opal}^{\mathrm{f} / / \mathrm{fl}} ; \mathrm{Lck} \mathrm{Cre}^{+}$ thymocytes (Fig. S7B, C). Because our data pointed to a role for $\mathrm{Ca}^{2+}$ signaling defects upon Opal deletion, a phenotype observed also in other tissues [45], we decided to further investigate this crucial aspect of AICD. We took a twopronged approach and analyzed both gene expression of molecules involved in $\mathrm{Ca}^{2+}$ signaling as well as the dynamics of $\mathrm{Ca}^{2+}$ signaling in $\mathrm{Wt}$ and Opal-deficient T cells.

Using our RNAseq data set, we delved into the expression of genes encoding for different regulators of intracellular calcium signaling: IP3R, SERCA, ORAI channels, and the mitochondrial calcium uniporter (MCU). The MCU holoplex consists of the MCU ion pore, its negative regulatory subunit MCUb, the essential regulator Smdt1/ EMRE, the two regulatory subunits MICU1 and MICU2 (and the CNS paralogue MICU3), and the MICUR1 regulator [46]. This analysis showed $\mathrm{Ca}^{2+}$ genes were upregulated in the DN3-DN4 transition, and that deletion of Opal had no effect on the expression of these studied genes. Interestingly, the DN3 $\rightarrow$ DN4 transition appears to be crucial to enable mitochondrial $\mathrm{Ca}^{2+}$ uptake: while the core MCU holoplex components are all upregulated, the inhibitory MCU subunit MCUb is downregulated. Despite we did not find a " $\mathrm{Ca}^{2+}$ signaling signature" associated with Opal deletion, our previous studies showed that lack of Opal affects $\mathrm{Ca}^{2+}$ signaling by modifying the supramolecular organization of the MCU holoplex [45]. We therefore performed a set of functional $\mathrm{Ca}^{2+}$ measurements in ex vivo thymocytes and in Jurkat cells. In thymocytes challenged with ionomycin to evaluate maximal cytoplasmic calcium levels by Fluo-4 staining, we observed that maximal cytoplasmic $\mathrm{Ca}^{2+}$ levels where higher in Opal-deficient cells than in their WT counterparts. To evaluate the specific effect of OPA1 inhibition and deletion on intracellular $\mathrm{Ca}^{2+}$ changes downstream TCR activation, we turned to Jurkat cells that represent the standard in vitro model for TCR signaling studies. To inhibit Opa1, we treated Jurkat cells with the specific Opa1 inhibitor MYLS22 [35] and we downregulated $O P A I$ expression by siRNA. Both inhibition and downregulation of OPA1 resulted in higher maximal and residual cytoplasmic calcium levels (Fig. S8A, B). Overall, these data suggest that Opal deficiency alters TCR signaling in thymocytes, possibly contributing to their higher susceptibility to apoptosis.

\section{Lymphopenia and functional defects in mature T cells from Opa1 thymocyte knockout mice}

To verify if the alteration in $\mathrm{T}$ cell development observed upon early Opal deletion reverberated in mature T cells, we first analyzed the hematological profile of WT;Lck-Cre ${ }^{+}$ and $\mathrm{Opa} 1^{\mathrm{f} / \mathrm{fl}} ; \mathrm{Lck}^{-\mathrm{Cre}^{+}}$mice. Total blood count analysis 
A

- Wt;:Lck-CRE ${ }^{+}$

- Opa1 $1^{\text {fl|fili:Lck-CRE }}$

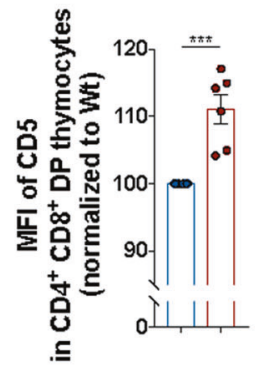

$\mathrm{B}$

- Wt:Lck-CRE ${ }^{+}$

- Opa1 ${ }^{\text {flifil:Lck-CRE }}$

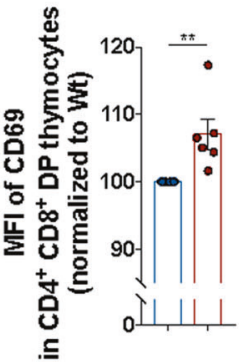

C

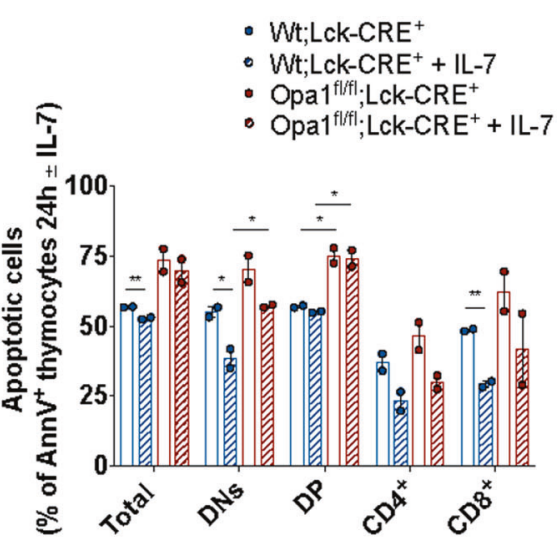

$\mathrm{D}$

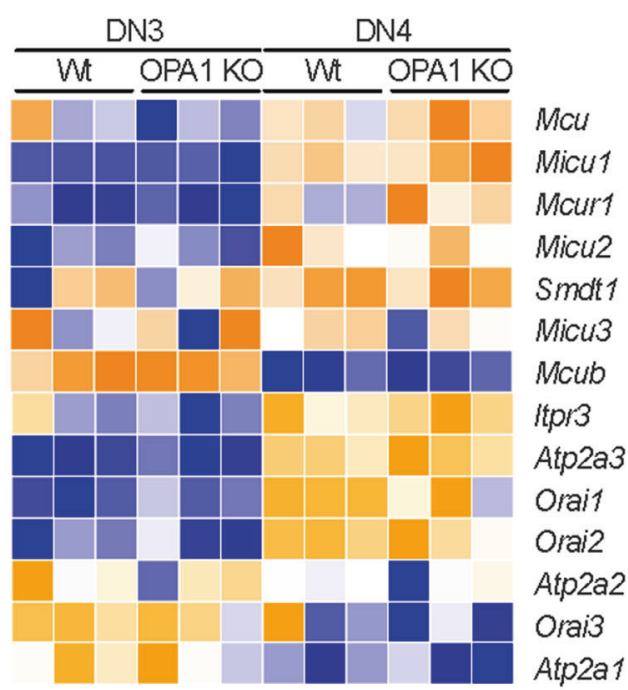

Fig. 3 Opa1 deficiency alters TCR and calcium signaling with increased susceptibility to apoptosis. A MFI of CD5 in WT;Lck-Cre ${ }^{+}$ and $\mathrm{Opal}^{\mathrm{f} / \mathrm{fl}} ; \mathrm{Lck}-\mathrm{Cre}^{+}$analyzed by flow cytometry. Data are mean \pm SEM $(N=6)$. B MFI of CD69 in WT;Lck-Cre ${ }^{+}$and Opa ${ }^{\text {fl/fl }} ;$ Lck-Cre $^{+}$ analyzed by flow cytometry. Data are mean \pm SEM $(N=6)$. C Frequencies of apoptotic cells ( $\mathrm{AnnV}^{+}$cells) in WT;Lck-Cre ${ }^{+}$and Opa ${ }^{\mathrm{fl} / \mathrm{fl}}$; Lck-Cre $^{+}$measured by flow cytometry $24 \mathrm{~h}$ after isolation and culture \pm IL-7. Data are mean $\pm \operatorname{SEM}(N=2)$. D Heatmap visualization of genes

showed no differences between knockout and WT animals (Fig. S9A). We delved further in the mature T cell compartment, first by analyzing mitochondrial morphology and ultrastructure in $\mathrm{CD}^{+}$lymphocytes sorted from spleens. We used WT;Lck-Cre ${ }^{+} ; \mathrm{mtYFP}^{\mathrm{tg} /+}$ and Opa ${ }^{\mathrm{fl} / \mathrm{fl}}$;Lck-Cre ${ }^{+}$; $\mathrm{mtYFP}^{\mathrm{tg} /+}$ mice to identify and sort Lck-Cre ${ }^{+} \mathrm{T}$ cells from spleens and to directly inspect mitochondrial morphology. Mitochondria were fragmented (Fig. 4A) and cristae swollen (Fig. 4B) in Opal-deficient, $\mathrm{mtYFP}^{+}, \mathrm{CD}^{+} \mathrm{T}$ cells compared to their $\mathrm{mtYFP}^{+} \mathrm{WT}$ counterparts. T cell function, activation, and differentiation are largely controlled by specific metabolic requirements: naïve and memory cells rely on OXPHOS, whereas activated effector cells are metabolically active, mostly depending on glycolysis for encoding for mitochondrial and cytoplasmic calcium handling regulators in DN3 and DN4 Opa ${ }^{\mathrm{f} / \mathrm{fl}} ; \mathrm{Lck}_{\mathrm{L}}-\mathrm{Cre}^{+}$versus WT;Lck-Cre ${ }^{+}$thymocytes ( $N=3$ /group). E Cytoplasmic calcium levels at baseline and after Ionomycin (Iono) in Opa ${ }^{\mathrm{f} / / \mathrm{fl}} ; \mathrm{Lck}_{\mathrm{C}} \mathrm{Cre}^{+}$versus WT; $\mathrm{Lck}^{-C r e}{ }^{+}$thymocytes. Data are mean \pm SEM $(N=4)$. F Maximal cytoplasmic calcium level in Opal ${ }^{\mathrm{f} / \mathrm{fl}} ; \mathrm{Lck}^{-C r e}{ }^{+}$versus WT;Lck-Cre ${ }^{+}$thymocytes. Data are mean $\pm \operatorname{SEM}(N=4)$.

ATP generation [47]. Given the profound mitochondrial changes recorded in $\mathrm{Opal}^{-1-}, \mathrm{mtYFP}^{+}, \mathrm{CD}^{+} \mathrm{T}$ cells, we compared $\mathrm{T}$ cell differentiation and activation in WT and Opal $^{-1-} \mathrm{CD}^{+} \mathrm{T}$ cells. Total $\mathrm{T}$ cells $\left(\mathrm{CD}^{+}\right)$as well as $\mathrm{CD}^{+}$and $\mathrm{CD}^{+} \mathrm{T}$ cells subsets were reduced in Opa $1^{\mathrm{f} / \mathrm{fl}}$; Lck-Cre $^{+} ; \mathrm{mtYFP}^{\mathrm{tg} /+}$ mice (Fig. 4C, D), suggesting the development of lymphopenia. Interestingly, while $\mathrm{CD}^{+}$ and $\mathrm{CD}^{+}$relative abundance was not altered in Opa $1^{\mathrm{fl} / \mathrm{fl}}$; Lck-Cre $^{+}$;mtYFP ${ }^{\text {tg/+ }}$ mice (Fig. S9B, C), the frequency of $\mathrm{CD}^{+} \mathrm{CD}^{-} \mathrm{CD}^{-} \quad \mathrm{T}$ (DNT) cells was increased (Fig. S9C-E). These cells represent an immunoregulatory $\mathrm{T}$ cell subset, sharing some features and surface markers with CD4 Treg and NK cells [48] and frequently expressing $\gamma \delta$ chains. Furthermore, we observed a reduction of Naïve 
A

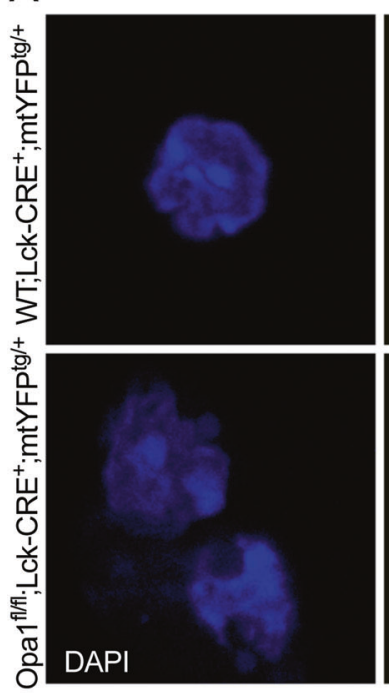

C

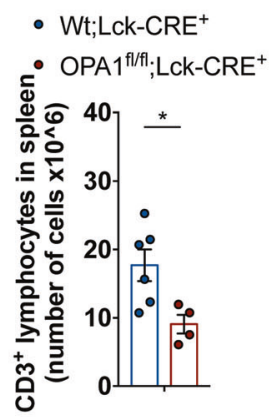

$\mathrm{F}$

$$
\rightarrow \text { IL-2 T } \mathrm{E} \text { Wt;Lck-CRE }
$$$$
\text { - IL-2 T } \text { Opa }^{\text {fl/fl/:Lck-CRE }}{ }^{+}
$$

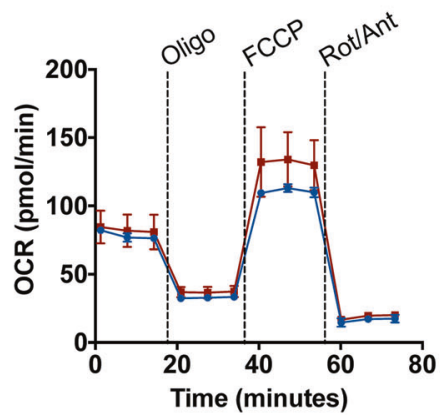

B
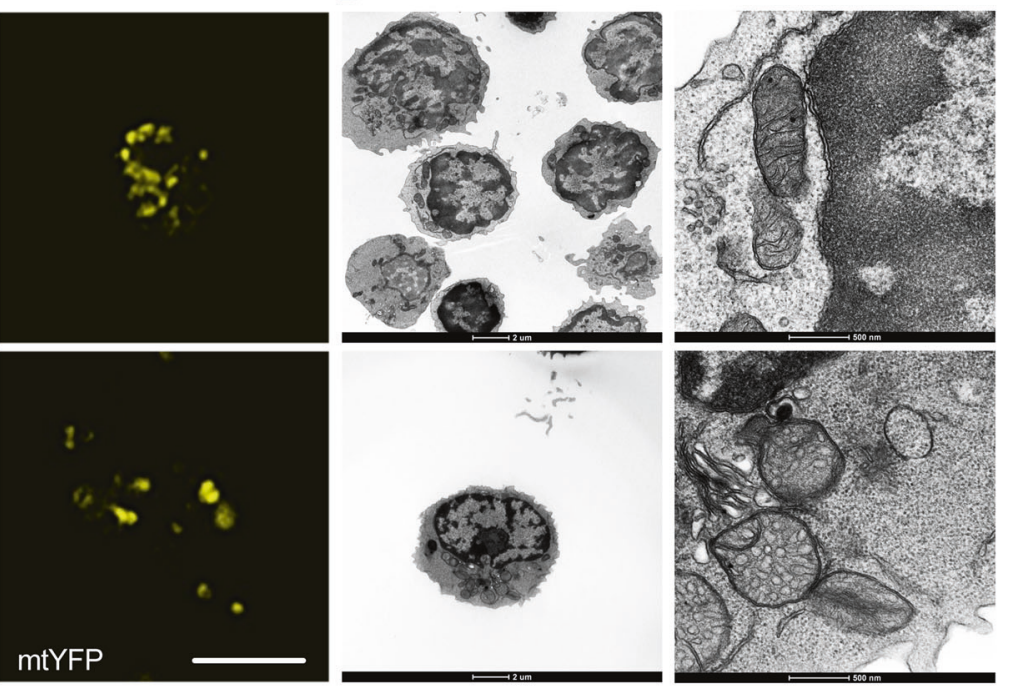

E

- $W t ;$ Lck-CRE ${ }^{+}$

- OPA $1^{\mathrm{flffl}} ; \mathrm{LCk}^{-C R E^{+}}$

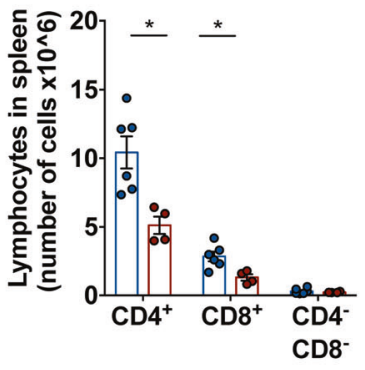

G

$\rightarrow$ IL-15 T $M$ Wt; Lck-CRE ${ }^{+}$

- IL-15 $\mathrm{T}_{\mathrm{M}}$ Opa ${ }^{\mathrm{fl/fl} ; \text { Lck-CRE }^{+}}$

$\mathrm{H}$

- WT;LCk-CRE ${ }^{+}$

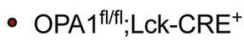

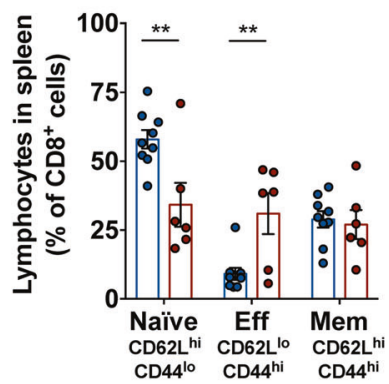

- Wt;Lck-CRE ${ }^{+}$

- Opa ${ }^{1 / f / f} ;$ Lck-CRE $^{+}$
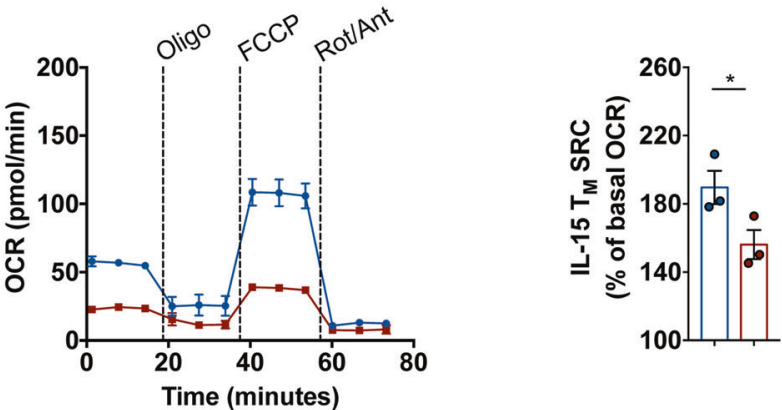

(CD62 $\left.\mathrm{L}^{\text {high }} \mathrm{CD} 44^{\text {low }}\right) \mathrm{CD}^{+} \mathrm{T}$ cells and the accumulation of effector memory (CD62 ${ }^{\text {low }} \mathrm{CD} 44^{\text {high }}$ ) $\mathrm{CD}^{+} \mathrm{T}$ cells in homeostatic condition (i.e., without any infection) in $\mathrm{Opa}^{\mathrm{t} / \mathrm{f} / \mathrm{i}} ;$ Lck-Cre $^{+}$mice (Fig. 4E). This immunophenotype could mirror the activated phenotype of thymocytes during maturation, characterized by the CD5 and CD69 upregulation in DP thymocytes (Fig. 3A, B). The accumulation of effector memory $\mathrm{T}$ cells in homeostatic conditions was not surprising, given that OPA1 is dispensable for $\mathrm{T}_{\mathrm{E}}$ cells development [24]. We further verified if Opal deletion during early thymocyte development affected the generation and the metabolism of $\mathrm{T}_{\mathrm{M}}$ and $\mathrm{T}_{\mathrm{E}}$ cells generated in vitro by treating $\mathrm{CD}^{+} \mathrm{T}$ cells with $\mathrm{IL}-15$ and $\mathrm{IL}-2$, respectively. The metabolism of $\mathrm{T}_{\mathrm{E}}$ cells was not affected by Opal deficiency (Fig. 4F). Indeed, OXPHOS defects were not apparent in in vitro generated Opal-deficient $\mathrm{T}_{\mathrm{E}}$ cells 
Fig. 4 Opa1 deficiency generates structurally, functionally, and metabolically impaired mature $\mathrm{CD8}^{+} \mathbf{T}$ cells. A Representative confocal images of mtYFP fluorescence in $\mathrm{CD}^{+}$lymphocytes freshly isolated from WT; $\mathrm{Lck}_{-\mathrm{Cre}}^{+} ; \mathrm{mtYFP}^{+}$and $\mathrm{Opa}^{\mathrm{fl} / \mathrm{fl}} ; \mathrm{Lck}^{-\mathrm{Cre}^{+}} ; \mathrm{mtYFP}^{+}$ mice. Scale bar: $5 \mu \mathrm{m}$. B Representative electron micrographs of CD8 ${ }^{+}$ lymphocytes freshly isolated from WT;Lck-Cre ${ }^{+}$and Opa $1^{\mathrm{fl} / \mathrm{fl}} ; \mathrm{Lck}^{-\mathrm{Cre}^{+}}$ mice. Scale bars: $2 \mu \mathrm{m}$ or $500 \mathrm{~nm}$ as indicated. C Cellularity of $\mathrm{CD}^{+}$ splenocytes in WT; $\mathrm{Lck}_{-} \mathrm{Cre}^{+}$and Opa1 ${ }^{\mathrm{f} / \mathrm{fl}} ; \mathrm{Lck} \mathrm{Cre}^{+}$mice. Each symbol represents an individual mouse. Each dot represents an individual mouse $\left(N=4 / 6\right.$ each group). Mean \pm SEM are reported. D Cellularity of $\mathrm{CD}^{+}$, $\mathrm{CD}^{+}$, and $\mathrm{CD}^{-}{ }^{-} \mathrm{CD}^{-}$splenocytes in WT; Lck-Cre $^{+}$and Opa ${ }^{\mathrm{f} / \mathrm{fl}}$;Lck$\mathrm{Cre}^{+}$mice. Each dot represents an individual mouse $(N=4 / 6$ each group). Mean \pm SEM are reported. E Frequencies of naive, effector, and memory CD8+ T lymphocytes in WT; Lck-Cre ${ }^{+}$and Opa $1^{\mathrm{f} / \mathrm{fll}} ; \mathrm{Lck}^{-C r e}{ }^{+}$ mice. Each dot represents an individual mouse $(N=6 / 9$ each group). Mean \pm SEM are reported. F OCR of WT; Lck-Cre $^{+}$and Opa $1^{\mathrm{f} / \mathrm{fl}} ; \mathrm{Lck}-$ $\mathrm{Cre}^{+} \mathrm{CD}^{+} \mathrm{T}$ cells activated with $\alpha \mathrm{CD} 3 / \alpha \mathrm{CD} 28$ and differentiated in IL$2 \mathrm{~T}_{\mathrm{E}}$ cells for 6 days. OCR analysis at baseline and after exposure to oligomycin (Oligo), FCCP, and rotenone/antimycin (Rot/Ant). Data are representative of three independent experiments ( $N=3$ /group). G OCR of WT;Lck-Cre ${ }^{+}$and $\mathrm{Opa1}{ }^{\mathrm{f} / / \mathrm{l}} ; \mathrm{Lck}-\mathrm{Cre}^{+} \mathrm{CD}^{+} \mathrm{T}$ cells activated with $\alpha \mathrm{CD} 3 / \alpha \mathrm{CD} 28$ and differentiated in IL-15 $\mathrm{T}_{\mathrm{M}}$ cells for 6 days. OCR analysis at baseline and after exposure to oligomycin (Oligo), FCCP, and rotenone/antimycin (Rot/Ant). Data are representative of three independent experiments ( $N=3$ /group). H SRC of WT;Lck-Cre ${ }^{+}$and Opa ${ }^{\mathrm{f} / \mathrm{ff}}$; Lck-Cre $^{+} \mathrm{CD}^{+}{ }^{\mathrm{T}}$ cells treated as in $(\mathbf{F})$. Data are mean $\pm \operatorname{SEM}(N=3)$.

(Fig. 4F), in line with the glycolytic phenotype of these cells [24]. Conversely, in $\mathrm{Opal}^{-1-} \mathrm{T}_{\mathrm{M}}$ generated in vitro the basal OCR was reduced and the high SRC typical of WT $\mathrm{T}_{\mathrm{M}}$ was abolished (Fig. 4G, H). Thus, OPA1 is essential to generate metabolically fit $\mathrm{T}_{\mathrm{M}}$. In sum, the absence of Opal during thymocyte development results in mitochondrial, functional, and metabolic defects affecting mature $\mathrm{T}$ cells in peripheral lymphoid tissues.

\section{Discussion}

Despite the emerging role of metabolism in the immune response [47], the question of whether and how mitochondrial dynamics and OPA1 specifically direct $\mathrm{T}$ cell development remains unanswered. Here, we found that DN3 $\mathrm{T}$ cell progenitors predominantly rely on OXPHOS over glycolysis and that OPA1 is required for $\beta$-selection and generation of metabolically competent mature lymphocytes.

Thymic development is particularly sensitive to perturbation of mitochondrial content and function [11-13, 4951]. Mitochondria are less abundant in mature $\mathrm{T}$ cells than thymocytes and are cleared by increased levels of autophagy during their development $[52,53]$. Of note, mitochondrial dynamics and autophagy crosstalk in the regulation of AICD [26, 27], which suggests that unbalanced mitochondria quality control might result in lymphocyte functional deficiencies or autoimmunity. Our data show how the absence of OPA1, a master regulator of IMM fusion and ETC supercomplexes organization, hijacks thymocyte metabolism and development starting from $\beta$ selection stage.

NOTCH signaling is critical during thymocyte maturation. It promotes survival of pre-T cells at the $\beta$-selection checkpoint $[5,10,11]$ and together with IL-7 and mTORC signaling determines proliferation and $\mathrm{T}$ cell lineage commitment [6, 13, 54]. Interestingly, mitochondrial fusion directs the differentiation of cardiomyocytes via Calcineurin and NOTCH signaling [55]. Our current data suggest the crosstalk between mitochondrial shape and NOTCH signaling might also extend to thymocyte development.

Thymocyte maturation requires coordinated and controlled cell movement and migration in the different areas of the thymus, which consists anatomically of two interconnected lobes divided in a cortical area (cortex) and inner area (medulla) [56]. $\mathrm{T}$ cell progenitors, after entering the organ, migrate toward the cortex where they progress in maturation up to DP stage before reaching the medulla to complete negative selection and single positive $\mathrm{T}$ cell commitment [57]. Mitochondrial fragmentation and relocation to the uropod (the posterior area) of a migrating cell is necessary to allow proper chemotaxis and migration [18]. DRP1 ablation results in altered in vitro and in vivo thymocyte migration in the medullary area [20]. It is tempting to speculate that a similar migratory defect might affect Opal-deficient cells. Of note, the higher expression of CD5 and CD69 in DP thymocytes might indeed also reflect longer persistence in the cortex due to a cell migration deficit.

Opal deficiency results in impaired long-term immune protection due to the bioenergetic failure of memory $\mathrm{T}$ cells to sustain their viability $[24,47]$. Our data show that Opal deficiency starting from early thymocyte development results in lymphopenia and metabolic defects in mature $\mathrm{T}$ cells. Moreover, our data suggest that the absence of OPA1 might result in the generation of abnormally activated $\mathrm{T}$ cells, possibly contributing to inflammation in a mechanism similar to the one observed for other mitochondrial functional deficiencies [58-60].

Interestingly, mice with $\mathrm{T}$ cell specific deletion of OPA1 are lymphopenic but accumulate the immunoregulatory population of $\mathrm{CD}^{+} \mathrm{CD} 4^{-} \mathrm{CD} 8^{-}$DNT cells predominantly expressing TCR $\gamma \delta$. This phenotype resembles one of the pathologic features of aplastic anemia [61], a condition where the insufficient number of hematopoietic cells produced in the bone marrow leads to higher susceptibility to infections. Nevertheless, whether human $\mathrm{CD}^{+}{ }^{+} \mathrm{CD} 4^{-} \mathrm{CD} 8^{-}$ DNT show a similar mitochondrial bioenergetic defect and whether a genetic or pharmacological insult to mitochondria in the hematopoietic compartment might contribute to the development of aplastic anemia are not known.

While Opal deletion impairs mitochondrial respiration and $\beta$-selection in thymocytes, OPA1 overexpression does 
not affect $\mathrm{T}$ cell development. It remains to be investigated whether OPA1 overexpression confers in vivo survival or metabolic advantage which might, on one side, favor the generation of metabolically fit pool of long-lived memory $\mathrm{T}$ cells while, on the other side, be detrimental in autoimmune condition where cell death is central to control and limit $\mathrm{T}$ cell-mediated tissue damage.

In conclusion, the deletion of Opal early in the $\mathrm{T}$ cell lineage hampers mitochondrial respiration at the DN3 stage and $\beta$-selection. Moreover, Opal deficiency leads to abnormally activated mature $\mathrm{T}$ cells that might possess a pro-inflammatory phenotype.

\section{Material and methods}

\section{Mice}

$O p a 1^{\mathrm{fl} / \mathrm{fl}}$ mice are described elsewhere [23]. Mito-YFP mice were a kind gift from Nils-Göran Larsson (Karolinska Institute, University of Stockholm) [31]. Lck-CRE mice (strain ID 003802) were purchased form Jackson lab. Mice were maintained in C57BL6 background and used for experiments between 6 and 8 weeks of age. All mice were bred and maintained under approved protocols (protocol 32/2011 CEASA and 318/2015 Italian Ministry of Health to LS).

\section{Cell culture and treatments}

Jurkat cells were cultured in 1640 media supplemented with $10 \%$ FCS, 4 mM L-glutamine, $1 \%$ penicillin/streptomycin, and $55 \mu \mathrm{M} \beta$-mercaptoethanol under $5 \% \mathrm{CO}_{2}$, atmospheric oxygen, at $37^{\circ} \mathrm{C}$ in a humidified incubator. For MYLS22 treatment, cells were washed and resuspended in RPMI supplemented with $2 \%$ FCS and $50 \mu \mathrm{M}$ MYLS22 for $2 \mathrm{~h}$ before the experiment was started. The following siRNA have been used: Control Silencer siRNA (4390843) and OPAl silencer siRNA (4392420 ID s9850) from ThermoFisher. Jurkat cells were electroporated with $100 \mathrm{nM}$ siRNA using Neon Transfection System (Invitrogen) following manufacturer's protocol. Cells were analyzed $24 \mathrm{~h}$ after electroporation.

\section{Flow cytometry}

Fluorochrome-conjugated monoclonal antibodies were purchased from eBioscience, BD Pharmingen, or Biolegend. Single cell suspension were prepared form thymus or spleens of WT; $\mathrm{Lck}_{-C r e}{ }^{+}$and $\mathrm{Opa}^{\mathrm{f} / \mathrm{fl}} ; \mathrm{Lck}-\mathrm{Cre}^{+}$mice. Erythrocytes were eliminated by $10 \mathrm{~min}$ incubated with ACK buffer (ThermoFisher). Equal number of cells were stained with indicated antibodies diluted 1:200 in PBS supplemented with $1 \% \mathrm{BSA}$ for $20 \mathrm{~min}$ at $4{ }^{\circ} \mathrm{C}$. MitoTracker Green and TMRM staining were performed according to the manufacturer's instructions (Life Technologies). Equal number of thymocytes were loaded with $15 \mathrm{nM}$ MitoTracker Green or $2 \mathrm{nM}$ TMRM for $30 \mathrm{~min}$ at $37^{\circ} \mathrm{C}$ in humidified incubator. $\mathrm{CsH}(0.5 \mu \mathrm{M})$ was added to each sample to inhibit the multidrug resistance pump. Acquisition and analysis were performed using a FACSCanto $^{\mathrm{TM}}$ II and FlowJo software (BD Biosciences).

\section{Confocal imaging}

Mito-YFP ${ }^{+}$cells from WT;Lck-Cre ${ }^{+}$and Opa1 ${ }^{\mathrm{f} / \mathrm{fl}} ;$ Lck-Cre $^{+}$ mice were sorted using a FACSAria ${ }^{\mathrm{TM}}$ Illu Cell Sorter (BD Biosciences) and fixed on poly-D-lysine pre-coated slides. For confocal images, microscope slides were placed on the stage of a LSM510 Zeiss confocal imaging system using a Plan Apochromat $\times 63$ 1.4 NA Oil DIC objective or on a Nikon A1r microscope using a $\times 40$ CFI Plan APO VC 1.4 NA DT:0.13 mm objective. Stacks of images separated by $0.4 \mu \mathrm{m}$ along the $z$-axis were acquired. Then, three-dimensional reconstruction of the mitochondrial stacks was performed with ImageJ $1.44 \mathrm{o}(\mathrm{NIH})$.

\section{Electron microscopy}

$\mathrm{T}$ cells $\left(2 \times 10^{6}\right)$ were fixed in $2.5 \%$ glutaraldehyde in $100 \mathrm{mM}$ sodium cacodylate, washed in cacodylate buffer. After dehydration samples were embedded in Eponate 12 resin (Ted Pella) and sections were cut. Images were acquired using a FEI Tecnai 12 Transmission electron microscope equipped with a Veleta digital camera. Brightness and contrast were adjusted using ImageJ $1.44 \mathrm{o}(\mathrm{NIH})$.

\section{Western blotting}

Cells were washed with ice cold PBS and lysed in 1x lysis buffer (Cell Signaling Technologies) supplemented with $1 \mathrm{mM}$ PMSF and protease inhibitors. Samples were incubated $30 \mathrm{~min}$ on ice before being centrifuged at $20,000 \times g$ for $10 \mathrm{~min}$ at $4{ }^{\circ} \mathrm{C}$. Cleared protein lysate was denatured with LDS loading buffer for $10 \mathrm{~min}$ at $90{ }^{\circ} \mathrm{C}$. Samples were run on precast $4-12 \%$ bis-tris protein gels (Life Technologies). Proteins were transferred onto nitrocellulose membranes using an iBLOT 2 system (Life Technologies). Membranes were blocked with $5 \%$ w/v milk and $0.1 \%$ Tween-20 in TBS and incubated with the appropriate antibodies in $5 \% \mathrm{w} / \mathrm{v}$ BSA in TBS with $0.1 \%$ Tween-20 overnight at $4{ }^{\circ} \mathrm{C}$. The following antibodies were used: antiOPA1 (BD Biosciences, Cat\# 612606) and anti-Actin (CST, Cat\# 4970S). All primary antibody incubations were followed by incubation with secondary HRP-conjugated antibody (Pierce) in 5\% milk and $0.1 \%$ Tween-20 in TBS and visualized using SuperSignal West Pico or Femto Chemiluminescent Substrate (Pierce). 


\section{Metabolic phenotyping}

OCR and ECAR were measured in XF media (non-buffered RPMI 1640 containing $25 \mathrm{mM}$ glucose, $2 \mathrm{mM} \mathrm{L}$-glutamine, and $1 \mathrm{mM}$ sodium pyruvate) under basal conditions and in response to $3 \mu \mathrm{M}$ etomoxir (Tocris), $1 \mu \mathrm{M}$ oligomycin, 1.5 $\mu \mathrm{M}$ FCCP, and $100 \mathrm{nM}$ rotenone $+1 \mu \mathrm{M}$ antimycin $\mathrm{A}$, using a 96 well XF or XFe extracellular flux analyzer (Seahorse Bioscience).

\section{Calcium measurements}

Thymocytes $\left(3 \times 10^{6}\right)$ were loaded for $30 \mathrm{~min}$ at $37^{\circ} \mathrm{C}$ in humidified incubator with $6 \mu \mathrm{M}$ Fluo-4 dissolved in HBSS supplemented with calcium and magnesium (Sigma H8264) in the presence of $0.5 \mu \mathrm{M} \mathrm{CsH}$. Cells were then washed and resuspended in $300 \mu \mathrm{l}$ of HBSS + calcium and magnesium supplemented with $0.5 \mu \mathrm{M} \mathrm{CsH}$. Fluo-4 fluorescence was acquired using the AF488 channel of the cytofluorimeter. We acquired the basal fluorescence for $30 \mathrm{~s}$ followed by Ionomycin treatment (final concentration $500 \mathrm{ng} / \mathrm{mL}$ ) to evaluate maximal calcium flux.

Jurkat cells $\left(3 \times 10^{6}\right)$ were loaded $30 \mathrm{~min}$ at $37^{\circ} \mathrm{C}$ in a humidified incubator with $2 \mu \mathrm{M}$ Indo-AM dissolved in complete medium supplemented with $0.5 \mu \mathrm{M} \mathrm{CsH}$. Cells were washed and resuspended in $300 \mu \mathrm{l}$ of complete medium supplemented with $0.5 \mu \mathrm{M} \mathrm{CsH}$ and $5 \mu \mathrm{g} / \mathrm{ml}$ mouse antihuman CD3 (clone OKT3, Invitrogen Cat\#16-0037-85) for $30 \mathrm{~min}$ at $4{ }^{\circ} \mathrm{C}$ in the dark. Indo-violet and indo-blue were acquired in the linear scale of the cytofluorimeter. Tubes were placed in a $37^{\circ} \mathrm{C}$ temperature-controlled tube holder and after $45 \mathrm{~s}$ acquisition was initiated. After $30 \mathrm{~s}$ of basal fluorescence recordings, antiCD3 crosslinking was performed by incubating for 6 min with an anti-mouse $\operatorname{IgG}$ (Fc-specific) biotin crosslinking antibody (Sigma, B7401, diluted 1:50 directly in the acquisition tube).

\section{Complete blood count}

Blood from WT;Lck-Cre ${ }^{+}$and Opa ${ }^{\mathrm{f} / \mathrm{fl}} ; \mathrm{Lck}^{\mathrm{L}-\mathrm{Cre}^{+}}$mice was collected in heparin coated tubes and analyzed with a CELL-Dyn Emerald hematology analyzer (Abbott, IL, USA).

\section{RNAseq}

RNA isolation was performed using the RNeasy kit (Qiagen) as per manufacturer's instructions and RNA was quantified using Qubit 2.0 (ThermoFisher Scientific). Libraries were prepared using the TruSeq stranded mRNA kit (Illumina) and sequenced in a HISeq 3000 (Illumina) by the Deep-Sequencing Facility at the Max Planck Institute for Immunobiology and Epigenetics. Sequenced libraries were processed in an in-house developed RNAseq pipeline [62] that employs deepTools for Quality control [63, 64], Cutadapt for trimming [65], STAR [66] for mapping and featureCounts [67] to quantify mapped reads. Raw counts of mapped reads were processed in $\mathrm{R}$ (Lucent Technologies) with DESeq2 [68] to determine differentially expressed genes and generate normalized read counts to visualize as heatmaps using Morpheus (Broad Institute).

\section{Statistical analysis}

Flow cytometry data were analyzed using FlowJo 10 (BD Biosciences). Statistical analysis was performed using Prism 7 software (GraphPad) and results are represented as Mean \pm SEM. Individual independent experiments are shown as dots overlaid on the interval graphs. All the acquisitions of the experiments have been performed blinded without knowing the specific condition of each sample. Comparisons between two groups were calculated using unpaired two-tailed Student's $t$ tests. Comparisons among more than two groups were calculated using oneway ANOVA with Bonferroni's multiple comparison tests. We observed normal distribution and no difference in variance between groups in individual comparisons. Selection of sample size was based on extensive experience with metabolic assays. ${ }^{*} p<0.05,{ }^{*} p<0.01, * * * p<$ 0.001 .

\section{Data availability}

RNAseq data are accessible at GEO under the accession number GSE165579. The other data sets used and/or analyzed during the current study are available from the corresponding author on reasonable request.

Acknowledgements We thank Dr. F. Caicci (Bioimaging Facility, Department of Biology, University of Padua) and Dr. A. Cabrelle (Flow Cytometry Facility, VIMM) for technical support with experiments; Dr. N.G. Larsson (Karolinska Institute) for the mtYFP $P^{\text {flxstop/flixstop }}$ mice.

Funding This work was funded by Swiss National Foundation (SNF 31-118171), Italian Ministry of Health (GR 09.021), Italian Ministry of Research (FIRB RBAP11Z3YA_005; PRIN 2017BF3PXZ), ERC (GA282280), AIRC (IG19991) to LS. MC was supported by a Humboldt Fellowship from the Alexander von Humboldt Foundation.

Author contributions MC and LS conceived the project and wrote the paper. DS and MG performed and analyzed experiments. NR performed bioinformatic analysis. ELP conceptualized experiments. All authors edited the paper; LS supervised the project.

\section{Compliance with ethical standards}

Conflict of interest LS is an inventor on a patent covering the use of MYLS22 as OPA1 inhibitor. The other authors declare no competing interests. 
Ethical approval Not applicable. No human subjects used in this study.

Publisher's note Springer Nature remains neutral with regard to jurisdictional claims in published maps and institutional affiliations.

Open Access This article is licensed under a Creative Commons Attribution 4.0 International License, which permits use, sharing, adaptation, distribution and reproduction in any medium or format, as long as you give appropriate credit to the original author(s) and the source, provide a link to the Creative Commons license, and indicate if changes were made. The images or other third party material in this article are included in the article's Creative Commons license, unless indicated otherwise in a credit line to the material. If material is not included in the article's Creative Commons license and your intended use is not permitted by statutory regulation or exceeds the permitted use, you will need to obtain permission directly from the copyright holder. To view a copy of this license, visit http://creativecommons. org/licenses/by/4.0/

\section{References}

1. Yui MA, Rothenberg EV. Developmental gene networks: a triathlon on the course to T cell identity. Nat Rev Immunol. 2014;14:529-45.

2. Carpenter AC, Bosselut R. Decision checkpoints in the thymus. Nat Immunol. 2010;11:666-73.

3. Laurent J, Bosco N, Marche PN, Ceredig R. New insights into the proliferation and differentiation of early mouse thymocytes. Int Immunol. 2004;16:1069-80.

4. Krangel MS. Mechanics of T cell receptor gene rearrangement. Curr Opin Immunol. 2009;21:133-9.

5. Ciofani M, Schmitt TM, Ciofani A, Michie AM, Cuburu N, Aublin A, et al. Obligatory role for cooperative signaling by preTCR and Notch during thymocyte differentiation. J Immunol. 2004;172:5230-9.

6. Boudil A, Matei IR, Shih HY, Bogdanoski G, Yuan JS, Chang SG, et al. IL-7 coordinates proliferation, differentiation and Tcra recombination during thymocyte beta-selection. Nat Immunol. 2015;16:397-405.

7. Starr TK, Jameson SC, Hogquist KA. Positive and negative selection of T cells. Annu Rev Immunol. 2003;21:139-76.

8. Lengle EE, Gustin NC, Gonzalez F, Menahan LA, Kemp RG. Energy metabolism in thymic lymphocytes of normal and leukemia AKR mice. Cancer Res. 1978;38:1113-9.

9. Chen H, Yang T, Zhu L, Zhao Y. Cellular metabolism on T-cell development and function. Int Rev Immunol. 2015;34:19-33.

10. Ciofani M, Zuniga-Pflucker JC. Notch promotes survival of pre-T cells at the beta-selection checkpoint by regulating cellular metabolism. Nat Immunol. 2005;6:881-8.

11. Swamy M, Pathak S, Grzes KM, Damerow S, Sinclair LV, van Aalten DM, et al. Glucose and glutamine fuel protein OGlcNAcylation to control $\mathrm{T}$ cell self-renewal and malignancy. Nat Immunol. 2016;17:712-20.

12. Ramstead AG, Wallace JA, Lee SH, Bauer KM, Tang WW, Ekiz $\mathrm{HA}$, et al. Mitochondrial pyruvate carrier 1 promotes peripheral $\mathrm{T}$ cell homeostasis through metabolic regulation of thymic development. Cell Rep. 2020;30:2889-99.e6.

13. Yang K, Blanco DB, Chen X, Dash P, Neale G, Rosencrance C, et al. Metabolic signaling directs the reciprocal lineage decisions of alphabeta and gammadelta T cells. Sci Immunol. 2018;3:eaas9818.

14. Hoshii T, Kasada A, Hatakeyama T, Ohtani M, Tadokoro Y, Naka $\mathrm{K}$, et al. Loss of mTOR complex 1 induces developmental blockage in early $\mathrm{T}$-lymphopoiesis and eradicates $\mathrm{T}$-cell acute lymphoblastic leukemia cells. Proc Natl Acad Sci USA. 2014;111:3805-10.

15. Giacomello M, Pyakurel A, Glytsou C, Scorrano L. The cell biology of mitochondrial membrane dynamics. Nat Rev Mol Cell Biol. 2020;21:204-24.

16. Chan DC. Mitochondrial dynamics and its involvement in disease. Annu Rev Pathol. 2020;15:235-59.

17. Pernas L, Scorrano L. Mito-Morphosis: mitochondrial fusion, fission, and cristae remodeling as key mediators of cellular function. Annu Rev Physiol. 2016;78:505-31.

18. Campello S, Lacalle RA, Bettella M, Manes S, Scorrano L, Viola A. Orchestration of lymphocyte chemotaxis by mitochondrial dynamics. J Exp Med. 2006;203:2879-86.

19. Baixauli F, Martin-Cofreces NB, Morlino G, Carrasco YR, Calabia-Linares C, Veiga E, et al. The mitochondrial fission factor dynamin-related protein 1 modulates T-cell receptor signalling at the immune synapse. EMBO J. 2011;30:1238-50.

20. Simula L, Pacella I, Colamatteo A, Procaccini C, Cancila V, Bordi $\mathrm{M}$, et al. Drp1 controls effective T cell immune-surveillance by regulating $\mathrm{T}$ cell migration, proliferation, and cMyc-dependent metabolic reprogramming. Cell Rep. 2018;25:3059-73.e10.

21. Cipolat S, Martins de Brito O, Dal Zilio B, Scorrano L. OPA1 requires mitofusin 1 to promote mitochondrial fusion. Proc Natl Acad Sci USA. 2004;101:15927-32.

22. Frezza C, Cipolat S, Martins de Brito O, Micaroni M, Beznoussenko GV, Rudka T, et al. OPA1 controls apoptotic cristae remodeling independently from mitochondrial fusion. Cell. 2006;126:177-89.

23. Cogliati S, Frezza C, Soriano ME, Varanita T, Quintana-Cabrera $\mathrm{R}$, Corrado $\mathrm{M}$, et al. Mitochondrial cristae shape determines respiratory chain supercomplexes assembly and respiratory efficiency. Cell. 2013;155:160-71.

24. Buck MD, O’Sullivan D, Klein Geltink RI, Curtis JD, Chang CH, Sanin DE, et al. Mitochondrial dynamics controls $\mathrm{T}$ cell fate through metabolic programming. Cell. 2016;166:63-76.

25. Arakaki R, Yamada A, Kudo Y, Hayashi Y, Ishimaru N. Mechanism of activation-induced cell death of $\mathrm{T}$ cells and regulation of FasL expression. Crit Rev Immunol. 2014;34:301-14.

26. Corrado M, Mariotti FR, Trapani L, Taraborrelli L, Nazio F, Cianfanelli V, et al. Macroautophagy inhibition maintains fragmented mitochondria to foster $\mathrm{T}$ cell receptor-dependent apoptosis. EMBO J. 2016;35:1793-809.

27. Simula L, Corrado M, Accordi B, Di Rita A, Nazio F, Antonucci $\mathrm{Y}$, et al. JNK1 and ERK1/2 modulate lymphocyte homeostasis via BIM and DRP1 upon AICD induction. Cell Death Differ. 2020;10:2749-67.

28. O'Connor RS, Guo L, Ghassemi S, Snyder NW, Worth AJ, Weng $\mathrm{L}$, et al. The CPT1a inhibitor, etomoxir induces severe oxidative stress at commonly used concentrations. Sci Rep. 2018;8:6289.

29. Molina TJ, Kishihara K, Siderovski DP, van Ewijk W, Narendran A, Timms E, et al. Profound block in thymocyte development in mice lacking p56lck. Nature. 1992;357:161-4.

30. Carow B, Gao Y, Coquet J, Reilly M, Rottenberg ME. lck-driven cre expression alters $\mathrm{T}$ cell development in the thymus and the frequencies and functions of peripheral T cell subsets. J Immunol. 2016;197:2261-8.

31. Sterky FH, Lee S, Wibom R, Olson L, Larsson NG. Impaired mitochondrial transport and Parkin-independent degeneration of respiratory chain-deficient dopamine neurons in vivo. Proc Natl Acad Sci USA. 2011;108:12937-42.

32. Reizis B, Leder P. Direct induction of T lymphocyte-specific gene expression by the mammalian Notch signaling pathway. Genes Dev. 2002;16:295-300.

33. Maillard I, Tu L, Sambandam A, Yashiro-Ohtani Y, Millholland J, Keeshan K, et al. The requirement for Notch signaling at the beta- 
selection checkpoint in vivo is absolute and independent of the pre-T cell receptor. J Exp Med. 2006;203:2239-45.

34. Kasahara A, Cipolat S, Chen Y, Dorn GW, Scorrano L. Mitochondrial fusion directs cardiomyocyte differentiation via calcineurin and Notch signaling. Science. 2013;342:734-7.

35. Herkenne S, Ek O, Zamberlan M, Pellattiero A, Chergova M, Chivite I, et al. Developmental and tumor angiogenesis requires the mitochondria-shaping protein Opa1. Cell Metab. 2020;31:987-1003.e1008.

36. Cogliati S, Calvo E, Loureiro M, Guaras AM, Nieto-Arellano R, Garcia-Poyatos C, et al. Mechanism of super-assembly of respiratory complexes III and IV. Nature. 2016;539:579-82.

37. Cheng CT, Qi Y, Wang YC, Chi KK, Chung Y, Ouyang C, et al. Arginine starvation kills tumor cells through aspartate exhaustion and mitochondrial dysfunction. Commun Biol. 2018;1:178.

38. Khater F, Lajoie M, Langlois S, Healy J, Cellot S, Richer C, et al. KMT2E-ASNS: a novel relapse-specific fusion gene in early T-cell precursor acute lymphoblastic leukemia. Blood. 2017;129:1729-32.

39. Chao de la Barca JM, Arrázola MS, Bocca C, Arnauné-Pelloquin L, Iuliano $\mathrm{O}$, Tcherkez $\mathrm{G}$, et al. The metabolomic signature of Opa1 deficiency in rat primary cortical neurons shows aspartate/glutamate depletion and phospholipids remodeling. Sci Rep. 2019;9:6107.

40. Rothenberg EV, Moore JE, Yui MA. Launching the T-cell-lineage developmental programme. Nat Rev Immunol. 2008;8:9-21.

41. Swat W, Dessing M, von Boehmer H, Kisielow P. CD69 expression during selection and maturation of $\mathrm{CD} 4+8+$ thymocytes. Eur J Immunol. 1993;23:739-46.

42. Azzam HS, Grinberg A, Lui K, Shen H, Shores EW, Love PE. CD5 expression is developmentally regulated by $\mathrm{T}$ cell receptor (TCR) signals and TCR avidity. J Exp Med. 1998;188:2301-11.

43. Joseph N, Reicher B, Barda-Saad M. The calcium feedback loop and $\mathrm{T}$ cell activation: how cytoskeleton networks control intracellular calcium flux. Biochim Biophys Acta. 2014;1838:557-68.

44. Scorrano L, Oakes SA, Opferman JT, Cheng EH, Sorcinelli MD, Pozzan T, et al. BAX and BAK regulation of endoplasmic reticulum $\mathrm{Ca} 2+$ : a control point for apoptosis. Science. 2003;300:135-9.

45. Herkenne S, Ek O, Zamberlan M, Pellattiero A, Chergova M, Chivite I, et al. Developmental and tumor angiogenesis requires the mitochondria-shaping protein Opa1. Cell Metab. 2020;31:987-1003 e1008.

46. Feno S, Rizzuto R, Raffaello A, Vecellio, Reane D. The molecular complexity of the mitochondrial calcium uniporter. Cell Calcium. 2020;93:102322.

47. Buck MD, Sowell RT, Kaech SM, Pearce EL. Metabolic instruction of immunity. Cell. 2017;169:570-86.

48. Hillhouse EE, Delisle JS, Lesage S. Immunoregulatory CD4(-) CD8(-) T cells as a potential therapeutic tool for transplantation, autoimmunity, and cancer. Front Immunol. 2013;4:6.

49. Zhao FL, Ahn JJ, Chen ELY, Yi TJ, Stickle NH, Spaner D, et al. Peroxisome proliferator-activated receptor-delta supports the metabolic requirements of cell growth in TCRbeta-selected thymocytes and peripheral $\mathrm{CD} 4(+) \mathrm{T}$ cells. $\mathrm{J}$ Immunol. 2018;201:2664-82.

50. Ouyang X, Han Y, Qu G, Li M, Wu N, Liu H, et al. Metabolic regulation of $\mathrm{T}$ cell development by Sin1-mTORC2 is mediated by pyruvate kinase M2. J Mol Cell Biol. 2019;11:93-106.
51. Tamas P, Macintyre A, Finlay D, Clarke R, Feijoo-Carnero C, Ashworth A, et al. LKB1 is essential for the proliferation of T-cell progenitors and mature peripheral $\mathrm{T}$ cells. Eur $\mathrm{J}$ Immunol. 2010;40:242-53.

52. Pua HH, Dzhagalov I, Chuck M, Mizushima N, He YW. A critical role for the autophagy gene Atg5 in T cell survival and proliferation. J Exp Med. 2007;204:25-31.

53. Pua HH, Guo J, Komatsu M, He YW. Autophagy is essential for mitochondrial clearance in mature $\mathrm{T}$ lymphocytes. J Immunol. 2009; 182:4046-55.

54. Ciofani M, Knowles GC, Wiest DL, von Boehmer H, ZunigaPflucker JC. Stage-specific and differential notch dependency at the alphabeta and gammadelta $\mathrm{T}$ lineage bifurcation. Immunity. 2006;25:105-16.

55. Kasahara A, Cipolat S, Chen Y, Dorn GW 2nd, Scorrano L. Mitochondrial fusion directs cardiomyocyte differentiation via calcineurin and Notch signaling. Science. 2013;342:734-7.

56. Pearse G. Normal structure, function and histology of the thymus. Toxicol Pathol. 2006;34:504-14.

57. Love PE, Bhandoola A. Signal integration and crosstalk during thymocyte migration and emigration. Nat Rev Immunol. 2011;11:469-77.

58. Tezze C, Romanello V, Desbats MA, Fadini GP, Albiero M, Favaro G, et al. Age-associated loss of OPA1 in muscle impacts muscle mass, metabolic homeostasis, systemic inflammation, and epithelial senescence. Cell Metab. 2017;25:1374-89.e6.

59. Rodriguez-Nuevo A, Diaz-Ramos A, Noguera E, Diaz-Saez F, Duran X, Munoz JP, et al. Mitochondrial DNA and TLR9 drive muscle inflammation upon Opa1 deficiency. EMBO J. 2018;37: e96553.

60. Baixauli F, Acin-Perez R, Villarroya-Beltri C, Mazzeo C, NunezAndrade N, Gabande-Rodriguez E, et al. Mitochondrial respiration controls lysosomal function during inflammatory $\mathrm{T}$ cell responses. Cell Metab. 2015;22:485-98.

61. Russell TB, Kurre P. Double-negative T cells are non-ALPSspecific markers of immune dysregulation found in patients with aplastic anemia. Blood. 2010;116:5072-3.

62. Bhardwaj V, Heyne S, Sikora K, Rabbani L, Rauer M, Kilpert F, et al. snakePipes: facilitating flexible, scalable and integrative epigenomic analysis. Bioinformatics. 2019;35:4757-9.

63. Afgan E, Baker D, van den Beek M, Blankenberg D, Bouvier D, Cech $\mathrm{M}$, et al. The Galaxy platform for accessible, reproducible and collaborative biomedical analyses: 2016 update. Nucleic Acids Res. 2016;44:W3-10.

64. Ramirez F, Ryan DP, Gruning B, Bhardwaj V, Kilpert F, Richter AS, et al. deepTools2: a next generation web server for deepsequencing data analysis. Nucleic Acids Res. 2016;44:W160-5.

65. Martin M. Cutadapt removes adapter sequences from highthroughput sequencing reads. 2011. 2011;17:3.

66. Dobin A, Davis CA, Schlesinger F, Drenkow J, Zaleski C, Jha S, et al. STAR: ultrafast universal RNA-seq aligner. Bioinformatics. 2013;29:15-21.

67. Liao Y, Smyth GK, Shi W. featureCounts: an efficient general purpose program for assigning sequence reads to genomic features. Bioinformatics. 2014;30:923-30.

68. Love MI, Huber W, Anders S. Moderated estimation of fold change and dispersion for RNA-seq data with DESeq2. Genome Biol. 2014;15:550. 